Arq. Bras. Med. Vet. Zootec., v.68, n.1, p.39-47, 2016

\title{
Sorovares e perfil de suscetibilidade a antimicrobianos em Salmonella spp. isoladas de produtos de origem suína
}

[Serovars and antimicrobial susceptibility of Salmonella spp. product isolated from swine]

\author{
A.L. Lima $^{1}$, D.P. Rodrigues ${ }^{2}$, M.S. Araújo ${ }^{2}$, E.M.F. Reis ${ }^{2}$, M.L. Festivo ${ }^{2}$, \\ E.C.P. Rodrigues ${ }^{3}$, N.S. Lázaro ${ }^{2}$
}

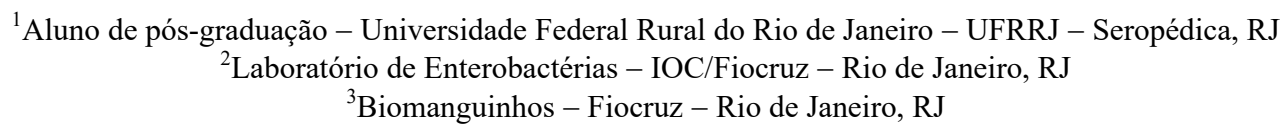

\section{RESUMO}

Foi analisado um total de 1824 cepas de Salmonella, isoladas de alimentos de origem suína, no período de janeiro/2005 a junho/2010. As cepas, provenientes de diferentes regiões do país, foram recebidas pelo Labent/IOC/FIocruz para caracterização antigênica conclusiva. Foram identificados 41 sorovares, destacando-se: Typhimurium, Derby, Enteritidis, Panama, Infantis e Anatum. Aspectos bacteriológicos e epidemiológicos relacionados a esses sorovares foram discutidos. O teste de suscetibilidade aos antimicrobianos foi realizado em 357 amostras, 257 (72\%) foram resistentes a uma ou mais drogas, e destas, 31,9\% mostraram-se multirresistentes. A variedade de sorovares observada neste estudo confirma o papel dos suínos na cadeia alimentar como importantes reservatórios de Salmonella, agravado ainda pelo elevado percentual de cepas resistentes a um ou mais antimicrobianos, alertando para uma condição de risco à saúde pública.

Palavras-chave: suínos, Salmonella zoonótica, saúde pública, resistência antimicrobiana

\begin{abstract}
We analyzed a total of 1824 strains of Salmonella isolated from swine-origin foods from January/2005 to June/2010. The strains from different regions of the country were received by Labent/IOC/FIOCRUZ for conclusive antigenic characterization. We identified 41 serovars, of which these stood out: Typhimurium, Derby, Enteritidis, Panama, Infantis and Anatum. Bacteriological and epidemiological aspects related to these serovars were discussed. The antimicrobial susceptibility test was performed on 357 samples, 257 (72\%) were resistant to one or more of these drugs and 31,9\% were multiresistant. A variety of serovars were identified reinforcing the swine as an important reservoir of Salmonella in the food chain. The high rates of antimicrobial resistance obtained in this evaluation may represent a risk condition to human health.
\end{abstract}

Keywords: pigs, zoonotic Salmonella, public health, antimicrobial resistance

\section{INTRODUÇÃO}

Os suínos são importantes reservatórios de diversos sorovares de Salmonella, revestindo-se de importância na veiculação desse microrganismo para o homem, seja pelo consumo de seus produtos ou mediante contaminação cruzada para outros alimentos.
Relatórios encaminhados pelo Laboratório de Referência Nacional de Enteroinfecções Bacterianas, LRNEB/IOC/Fiocruz à Coordenação Geral de Laboratórios de Saúde Pública, Ministério da Saúde, no período de 2005 a 2014, apontam progressão geométrica na incidência de Salmonella spp. entre cepas de origem humana, com percentuais mais elevados nas regiões Nordeste e Sudeste. Apesar da

Recebido em 18 de setembro e 2015

Aceito em 22 de setembro de 2015

E-mail: aloizioll@yahoo.com.br 
subnotificação, tem ocorrido aumento acentuado e contínuo do número de casos vinculados a determinados sorovares no Brasil, os quais variam geograficamente. Além disso, vem sendo observada uma inter-relação entre os sorovares incidentes em alimentos de origem animal e aqueles de origem humana (Rodrigues, 2011, 2014).

O conhecimento da epidemiologia da salmonelose é, portanto, de fundamental importância para o controle sanitário da doença, sendo o sorovar o marcador epidemiológico de eleição desse gênero. A sorotipagem, por ser uma técnica estável e relativamente simples, constitui uma importante ferramenta epidemiológica complementar na identificação de Salmonella, permitindo determinar a prevalência/emergência ou apontar tendências de um sorovar em distintas zonas geográficas, bem como identificar surtos, conhecer as fontes de infecção e as vias de transmissão (Rodrigues, 2011).

O crescente aumento da resistência aos antimicrobianos apresentada por Salmonella, incluindo drogas de última geração utilizadas na terapêutica humana, sublinha a necessidade de estudos que avaliem constantemente a circulação de cepas resistentes, tendo em vista a capacidade de disseminação dessas características para outras espécies ou ecossistemas.

Com base nessas circunstâncias, objetivou-se analisar a circulação dos sorovares (identificados no período de janeiro/2005 a junho/2010), entre Salmonella isoladas de alimentos de origem suína de diferentes regiões do Brasil, com ênfase especialmente na caracterização da resistência aos antimicrobianos, cujo conjunto de informações poderá ofertar subsídios que possam auxiliar no seu controle no país.

\section{MATERIAL E MÉTODOS}

A amostragem de estudo constituiu-se de 1824 amostras de Salmonella, isoladas de produtos de origem suína, no período de janeiro de 2005 a junho de 2010, relacionadas a alimentos envolvidos em surtos de origem alimentar (prato pronto), produtos industrializados e produtos oriundos de inspeção, em diferentes regiões do país. Todas as amostras, já apresentando uma identificação sumária do gênero, foram recebidas pelo Laboratório de Enterobactérias Labent/IOC/Fiocruz para confirmação do perfil bioquímico e caracterização antigênica conclusiva.

As culturas mantidas em ágar nutriente fosfatado foram inoculadas em caldo nutriente (Difco $\left.{ }^{\circledR}\right)$ e, logo após, semeadas em ágar entérico Hektoen (Oxoid®). Em sequência, as colônias foram repicadas simultaneamente em ágar nutriente inclinado e nos meios de triagem Costa e Vérnin (CV) e ágar lisina ferro (LIA), seguindo-se incubação a $37^{\circ} \mathrm{C} / 18$ a 24 horas. A complementação bioquímica foi efetuada mediante a semeadura em meio de SIM, para se comprovar a mobilidade, a ausência da produção de indol e de gás sulfídrico e a utilização do citrato como fonte única de carbono, provas essas que definem presuntivamente o gênero Salmonella, de acordo com os critérios estabelecidos por Costa e Hofer (1972).

Todas as amostras confirmadas bioquimicamente como pertencentes ao gênero Salmonella foram submetidas à caracterização antigênica por meio da técnica de soro aglutinação rápida em lâmina, com antissoros poli e monovalentes, somáticos e flagelares, produzidos no Labent, segundo as recomendações de Costa e Hofer (1972). A identificação do sorovar específico foi realizada com base no esquema sorológico de KauffmannWhite e representada de acordo com os critérios de Grimont e Weill (2007).

A susceptibilidade aos antimicrobianos foi realizada em $357(19,6 \%)$ das 1824 cepas, utilizando-se como critério a seleção de cerca de $20 \%$ das amostras isoladas a partir de alimentos. Esta foi determinada por disco-difusão, seguindo as recomendações preconizadas pelo Clinical and Laboratory Standards Institute - CLSI (atualizado anualmente), utilizando-se 11 fármacos da marca $\mathrm{OXOID} \AA$, representativos das classes de betalactâmicos (ampicilina - AMP $-10 \mu \mathrm{g}$, cefalotina $-\mathrm{CEP}-30 \mu \mathrm{g}$, ceftriaxona CRO $-30 \mu \mathrm{g}$, imipenem - IPM $-10 \mu \mathrm{g}$ ); fenicóis (cloranfenicol $-\mathrm{CHL}-10 \mu \mathrm{g}$ ); tetraciclinas

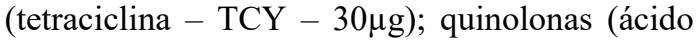
nalidíxico - NAL - 30 $\mu \mathrm{g}$, ciprofloxacina - CIP $5 \mu \mathrm{g}$ ); aminoglicosídeos (gentamicina GEN $10 \mu \mathrm{g}$ ); antifolatos (sulfametoxazol-trimetoprim -

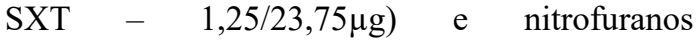
(nitrofurantoina - NIT $-300 \mu \mathrm{g}$ ). 
O critério de escolha tomou por base os antimicrobianos eletivos no controle e na terapêutica das enteroinfecções bacterianas, aqueles empregados como promotores de crescimento animal, drogas de última geração e orientações da OMS em relação aos antimicrobianos utilizados no monitoramento da resistência bacteriana.

Para o controle na qualidade de execução e na confiabilidade dos resultados obtidos, cepas padrão (Escherichia coli ATCC 25922, Escherichia coli ATCC 35218, Pseudomonas aeruginosa ATCC 27853, Enterococcus faecalis ATCC 29212 e Staphylococcus aureus ATCC 25923) foram testadas sob as mesmas condições de cultivo e incubação.

\section{RESULTADOS E DISCUSSÃO}

Entre as 1824 cepas de Salmonella spp., foram identificados 41 sorovares pertencentes à Salmonella enterica subespécie enterica (1822 cepas), destacando-se Salmonella ser. Typhimurium (26,5\%), Salmonella ser. Derby $(15,8 \%)$, Salmonella ser. Enteritidis $(8,8 \%)$, Salmonella ser. Panama (7,0\%), Salmonella ser. Infantis (6,8\%) e Salmonella ser. Anatum (6,1\%) por sua frequência (Tab. 1), e duas cepas de Salmonella enterica subespécie houtenae. É interessante notar ainda que Salmonella ser. Typhimurium, Salmonella ser. Derby e Salmonella ser. Enteritidis somadas representam mais da metade $(51,1 \%)$ das cepas isoladas. Observou-se ainda que os sorovares Typhimurium, Derby, Panama, Infantis, Anatum, Schwarzengrund, Bredeney, Ohio e London se apresentaram em todo o período de estudo, com predomínio de Salmonella ser. Typhimurium ao longo do período, exceto no ano de 2006, quando o sorovar Derby (22,3\%) ocorreu em maior número. Essa variedade de sorovares reforça ser o suíno uma importante fonte de infecção e veiculador, por meio de seus produtos, de salmonelas zoonóticas (Seixas et al., 2009).

Tabela 1. Frequência e distribuição dos sorovares de Salmonella de acordo com o ano de isolamento

\begin{tabular}{lcccccccc}
\hline \multicolumn{1}{c}{ Sorovares } & 2005 & 2006 & 2007 & 2008 & 2009 & 2010 & \multicolumn{2}{c}{ Total } \\
& $(\%)$ & $(\%)$ & $(\%)$ & $(\%)$ & $(\%)$ & $(\%)$ & $n$ & $(\%)$ \\
\hline Typhimurium & 20,4 & 16,3 & 29,2 & 36,6 & 34,1 & 24,1 & 483 & 26,5 \\
Derby & 16,2 & 23,0 & 16,4 & 12,2 & 11,7 & 11,5 & 289 & 15,8 \\
Enteritidis & 13,6 & 6,6 & 17,1 & 7,0 & 4,3 & 0 & 161 & 8,8 \\
Panama & 9,4 & 5,4 & 3,9 & 5,6 & 7,9 & 11,5 & 127 & 7,0 \\
Infantis & 6,2 & 9,4 & 6,0 & 6,6 & 6,4 & 3,4 & 124 & 6,8 \\
Anatum & 1,8 & 5,6 & 4,6 & 3,3 & 10,7 & 14,9 & 112 & 6,1 \\
Schwarzengrund & 4,7 & 6,6 & 1,1 & 1,4 & 4,0 & 3,4 & 72 & 3,9 \\
Brandenburg & 5,2 & 4,1 & 0,7 & 2,3 & 1,1 & 0 & 48 & 2,6 \\
Agona & 2,6 & 2,8 & 2,8 & 4,2 & 0,6 & 0 & 41 & 2,2 \\
Bredeney & 0,8 & 1,3 & 1,1 & 3,3 & 3,4 & 3,4 & 37 & 2,0 \\
Rissen & 1,0 & 2,5 & 5,3 & 0 & 1,3 & 0 & 35 & 1,9 \\
Ohio & 3,9 & 0,3 & 1,8 & 0,9 & 0,6 & 1,1 & 27 & 1,5 \\
London & 1,0 & 1,3 & 1,1 & 0,5 & 2,1 & 2,3 & 25 & 1,4 \\
Outros & 13,1 & 14,8 & 8,9 & 16,0 & 11,7 & 24,1 & 243 & 13,3 \\
\hline
\end{tabular}

A região Sul do Brasil destacou-se por apresentar o maior percentual de amostras (1721 cepas, $94,35 \%)$, seguida pelas regiões Centro-Oeste (61, $3,34 \%)$, Sudeste $(28,1,53 \%)$, Nordeste $(13,0,71 \%)$ e Norte (uma cepa, 0,05\%). O elevado número de cepas recebidas da região Sul sugere maior acompanhamento por parte dos órgãos fiscalizadores e empresas, somado ao reconhecimento de que a produção de suínos tem seu polo principal localizado nos estados de Santa Catarina e Rio Grande do Sul (ABIPECS, 2011).
Correlacionando as regiões do país com as fontes de isolamento e o sorovar, no computo geral, $90 \%$ das cepas eram oriundas de produtos industrializados, destacando-se as regiões Centro-Oeste e Sul, cujos índices mantiveram-se constantes durante o período de estudo. Índices inferiores foram observados para produtos de origem suína $(5,48 \%)$ envolvidos em surtos de doenças de transmissão alimentar e 4,5\% oriundos da Inspeção. O elevado percentual de cepas isoladas dentro da linha de produção da indústria reflete a carência e a necessidade de 
ações, provavelmente no início da cadeia de produção. Segundo Botteldoorn et al. (2004), mais de $70 \%$ das contaminações de carcaças por Salmonella spp. são originadas de suínos portadores que entram na linha de abate, principalmente pelo extravasamento de conteúdo intestinal durante a evisceração.

Por outro lado, embora em pequeno número, revestem-se de importância as cepas isoladas de surtos (prato pronto), particularmente Salmonella ser. Typhimurium e Salmonella ser. Enteritidis, tendo em vista que, no Brasil, a notificação de doenças transmitidas por alimentos não é obrigatória. Da mesma forma, a pequena amostragem de derivados de inspeção alerta para a necessidade de controle em toda a cadeia produtiva dos alimentos de origem animal, bem como de intensificação da vigilância sanitária, de modo a se obterem alimentos seguros para o consumo (Tab. 2).

Particularizando-se ainda esses resultados, de um modo geral, observou-se a ampla distribuição do sorovar Typhimurium em relação às fontes de isolamento e regiões do país, sendo variável nos demais sorovares. Por outro lado, Salmonella ser. Agona e Salmonella ser. Ohio foram identificadas apenas em produtos industrializados.

Tabela 2. Frequência das 1824 cepas de Salmonella de acordo com os sorovares, as fontes de isolamento e as regiões do país

\begin{tabular}{|c|c|c|c|c|c|c|c|c|c|c|c|c|c|c|c|}
\hline \multirow{2}{*}{ Sorovar } & \multicolumn{5}{|c|}{ Inspeção } & \multicolumn{5}{|c|}{ Prato Pronto } & \multicolumn{5}{|c|}{ Produtos Industrializados } \\
\hline & ${ }^{*} \mathrm{CO}$ & $\mathrm{NE}$ & $\mathrm{N}$ & $\mathrm{SE}$ & $\mathrm{S}$ & $\mathrm{CO}$ & $\mathrm{NE}$ & $\mathrm{N}$ & SE & $\mathrm{S}$ & $\mathrm{CO}$ & $\mathrm{NE}$ & $\mathrm{N}$ & SE & $\mathrm{S}$ \\
\hline Typhimurium & 0,16 & 0 & 0 & 0,11 & 0,6 & 0 & 0,33 & 0,05 & 0,33 & 0,49 & 0,65 & 0 & 0 & 0,2 & 23,57 \\
\hline Derby & 0,05 & 0 & 0 & 0,11 & 0,16 & 0 & 0 & 0 & 0 & 0,38 & 0,05 & 0 & 0 & 0,1 & 14,91 \\
\hline Enteritidis & 0 & 0 & 0 & 0 & 0,16 & 0 & 0 & 0 & 0,16 & 0,87 & 0,05 & 0 & 0 & 0 & 7,56 \\
\hline Panama & 0,33 & 0 & 0 & 0 & 0,11 & 0 & 0 & 0 & 0,05 & 0,38 & 0,16 & 0 & 0 & 0 & 5,86 \\
\hline Infantis & 0,05 & 0 & 0 & 0 & 0,22 & 0 & 0 & 0 & 0,11 & 0 & 0,11 & 0 & 0 & 0 & 6,14 \\
\hline Anatum & 0,05 & 0 & 0 & 0 & 0,22 & 0,11 & 0 & 0 & 0 & 0,22 & 0,22 & 0 & 0 & 0 & 5,31 \\
\hline Schwarzengrund & 0,05 & 0 & 0 & 0 & 0,33 & 0 & 0 & 0 & 0 & 0 & 0 & 0 & 0 & 0 & 3,56 \\
\hline Brandenburg & 0 & 0 & 0 & 0 & 0,22 & 0 & 0 & 0 & 0 & 0,05 & 0,05 & 0 & 0 & 0 & 2,3 \\
\hline Agona & 0 & 0 & 0 & 0 & 0 & 0 & 0 & 0 & 0 & 0 & 0,05 & 0 & 0 & 0 & 2,13 \\
\hline Bredeney & 0,11 & 0 & 0 & 0 & 0,05 & 0 & 0 & 0 & 0 & 0,11 & 0 & 0 & 0 & 0 & 1,75 \\
\hline Rissen & 0 & 0 & 0 & 0 & 0 & 0 & 0 & 0 & 0 & 0,33 & 0,05 & 0 & 0 & 0 & 1,53 \\
\hline Ohio & 0 & 0 & 0 & 0 & 0 & 0 & 0 & 0 & 0 & 0 & 0,16 & 0 & 0 & 0 & 1,31 \\
\hline London & 0 & 0 & 0 & 0 & 0,05 & 0 & 0 & 0 & 0 & 0,16 & 0 & 0 & 0 & 0 & 1,15 \\
\hline Outros & 0,27 & 0,38 & 0 & 0 & 0,65 & 0 & 0 & 0 & 0,16 & 1,15 & 0,54 & 0 & 0 & 0,2 & 10,25 \\
\hline Total & 1,09 & 0,38 & 0 & 0,22 & 2,79 & 0,11 & 0,33 & 0,05 & 0,82 & 4,16 & 2,13 & 0 & 0 & 0,5 & 87,39 \\
\hline
\end{tabular}

CO - Centro-Oeste; NE - Nordeste; N - Norte; SE - Sudeste; S - Sul.

Admitindo-se que o número de cepas analisadas não reflete, sob o ponto de vista epidemiológico, a incidência/prevalência de sorovares de Salmonella nessa espécie animal pelo fato de que elas foram recebidas aleatoriamente para caracterização antigênica, procurou-se fazer uma correlação com os dados apresentados por outros autores quanto à diversidade e circulação de sorovares.

Levantamentos realizados por Silva (2008) em suínos no Brasil apontam maior frequência de Salmonella ser. Derby, seguido dos sorovares Typhimurium, Give e London, em Mato Grosso. Já Tessmann et al. (2008) encontraram maior frequência de sorovares Infantis, Typhimurium, Panama e Derby, em Pelotas, Rio Grande do Sul. Ainda neste estado, Bessa et al. (2004) demonstraram que os sorovares Derby e Typhimurium foram isolados em $13,2 \%$ e $24,3 \%$, respectivamente, das 300 amostras de suínos analisadas. Estes dois sorovares também foram prevalentes em carcaças de suínos analisadas em frigoríficos em Santa Catarina por Seixas et al. (2009), indicando a possibilidade de essa bactéria contaminar os produtos elaborados com carne suína e, consequentemente, o consumidor.

Considerando o grande número de amostras oriundas de embutidos, 639 (35\%) das 1824 cepas estudadas, sendo 492 isoladas de linguiça tipo frescal (dados não evidenciados em tabela), procurou-se fazer uma avaliação quanto aos sorovares que apresentaram maior frequência nesse tipo de alimento em relação ao período de estudo. Entre os sorovares identificados nessa categoria, destacaram-se Typhimurium $(21,1 \%)$, Derby $(12,5 \%)$ e Panama $(8,3 \%)$ por sua frequência e distribuição em todo $\mathrm{o}$ período avaliado. A estes seguiram-se os 
sorovares Anatum (6,2\%), Infantis (5,3\%), Schwarzengrund $(4,7 \%)$, Enteritidis $(4,2 \%)$, Brandenburg (3,9\%), Rissen $(0,8 \%)$, Minnesota $(0,6 \%)$, London $(0,5 \%)$, Bredeney e Give $(0,3 \%)$.

A elevada frequência de cepas pertencentes aos sorovares Typhimurium e Derby em embutidos suínos neste estudo foi também observada no Brasil por Spricigo et al. (2008) em amostras de linguiça frescal, enquanto Castagna et al. (2004) obtiveram índices de $33,8 \%$ de Salmonella ser. Bredeney e $11,0 \%$ de Salmonella ser. Typhimurium em amostras de massa utilizadas na fabricação de embutidos tipo frescal. A elaboração da linguiça frescal requer uma série de etapas de manipulação, elevando as possibilidades de contaminação por uma gama de espécies de microrganismos, patogênicos ou deterioradores, podendo comprometer a qualidade microbiológica do produto final, desde que ocorram falhas e não conformidades em seu processamento (Marques et al., 2006).

Apesar de todos os sorovares de Salmonella serem considerados potencialmente patogênicos para o homem, a maioria dos surtos tem sido relacionada a apenas alguns sorovares, tais como Salmonella ser. Typhimurium, Salmonella ser. Enteritidis e Salmonella ser. Infantis (Rodrigues et al., 2014).

Salmonella ser. Typhimurium é considerado um dos principais sorovares envolvidos em casos de salmonelose em animais e no homem, destacando-se no Brasil por sua frequência em suínos e alimentos para consumo humano (Rodrigues et al., 2014). Outros sorovares, comuns em animais de produção, são raramente detectados no homem, como Derby, um dos mais frequentes em suínos (Stevens et al., 2009).
Contudo, mudanças importantes em relação à ocorrência de diferentes sorovares na população humana vêm sendo notificadas. Em 2008, este sorovar ocupou o sétimo lugar na lista dos 10 mais comumente isolados de fonte humana na União Europeia, representando aumento de 33\% em comparação ao ano anterior (EFSA, 2010).

De acordo com estudos realizados em 2008 nos EUA (CDC, 2009), do total de 8256 casos de infecção por Salmonella, identificados e sorotipados pelos laboratórios associados ao FoodNet, destacaram-se Salmonella ser. Enteritidis (22\%), Salmonella ser. Newport (14\%) e Salmonella ser. Typhimurium (13\%) entre os sorovares responsáveis por infecções de transmissão alimentar no homem.

Segundo Weill et al. (2006), entre as 168.034 cepas de Salmonella oriundas de fonte humana relatadas pelo NRC-Salm na França, no período de 1993 a 2003, Salmonella ser. Enteritidis e Salmonella ser.Typhimurium representavam os sorovares prevalentes $(35 \%$ e $32,5 \%$, respectivamente); nos anos de 1995 e 1997, entretanto, Salmonella ser.Typhimurium foi o mais frequente. No Brasil, estes sorovares encontram-se entre os mais frequentemente isolados nas duas últimas décadas, sendo notória sua participação em surtos de origem alimentar no homem (Rodrigues, 2011).

O teste de suscetibilidade aos antimicrobianos revelou que, das 357 amostras analisadas, 257 (72\%) foram resistentes a uma ou mais drogas. A maior taxa recaiu sobre TCY $(44,3 \%)$, seguido de NIT (34\%), NAL (25\%), AMP (18,8\%), SXT $(9,8 \%), \operatorname{CHL}(8,4 \%), \operatorname{GEN}(8,1 \%)$ e CEP $(3,7 \%)$ (Tab. 3).

Tabela 3. Frequência e distribuição da resistência antimicrobiana em 357 cepas Salmonella spp. provenientes de alimentos de origem suína entre jan./2005 e jun./2010

\begin{tabular}{lccccccc}
\hline Antimicrobianos & 2005 & 2006 & 2007 & 2008 & 2009 & 2010 & Total \\
\hline AMP - ampicilina & 15,4 & 9,2 & 18,8 & 32,4 & 30,4 & 6,7 & 18,8 \\
CEP - cefalotina & 2,2 & 1,0 & 0 & 10,8 & 8,5 & 0 & 3,7 \\
CHL - cloranfenicol & 11,1 & 7,1 & 13,2 & 10,8 & 8,5 & 0 & 8,4 \\
CIP - ciprofloxacina & 0 & 1,2 & 0 & 0 & 0 & 0 & 0,2 \\
CRO - ceftriaxona & 0 & 1,2 & 0 & 2,7 & 0 & 0 & 0,6 \\
GEN - gentamicina & 2,2 & 2,0 & 8,7 & 16,2 & 12,8 & 6,7 & 8,1 \\
IMP - imipenem & 0 & 0 & 0 & 0 & 0 & 0 & 0 \\
NAL - ác. nalidíxico & 30,8 & 14,3 & 26,1 & 27,0 & 38,3 & 13,3 & 25,0 \\
NIT - nitrofurantoína & 40,7 & 41,8 & 56,5 & 24,3 & 27,7 & 13,3 & 34,0 \\
SXT - sulfametoxazol/trimetoprim & 18,9 & 9,2 & 8,8 & 13,5 & 8,5 & 0 & 9,8 \\
TCY - tetraciclina & 47,2 & 37,7 & 47,8 & 35,1 & 38,3 & 60,0 & 44,3 \\
\hline
\end{tabular}


Resultados semelhantes foram encontrados por Spricigo et al. (2008) em amostras de linguiça frescal no município de Lages - SC para TCY $(41,67)$. Segundo os autores, o elevado percentual de resistência encontrado para tetraciclina e sulfonamida $(45 \%)$ poderia ser explicado pelo uso frequente desses antimicrobianos nos animais criados para a produção de alimentos. A frequência elevada de resistência à tetraciclina é um resultado presumível, pois esse fármaco é um dos mais antigos antimicrobianos usados tanto para tratamento quanto para promoção de crescimento. Entretanto, no Brasil, as tetraciclinas foram banidas em 1998 como aditivos alimentares em rações de animais, mas continuam sendo utilizadas na terapêutica (Rossi, 2005).

Percentuais elevados de resistência às sulfonamidas $(68 \%)$ e à tetraciclina $(60 \%)$, bem como à ampicilina (12\%), à gentamicina $(10 \%)$ e à ciprofloxacina $(2 \%)$, foram obtidos por Silva (2008) em amostras de Salmonella isoladas de suínos no Mato Grosso. Segundo o autor, o predomínio de amostras resistentes à tetraciclina, à estreptomicina e às sulfonamidas está provavelmente relacionado à ampla utilização desses fármacos nessa espécie animal.

Durante anos, ampicilina, sulfametoxazoltrimetoprim e cloranfenicol foram drogas de escolha no tratamento de infecções graves por Salmonella. No entanto, taxas crescentes de resistência a esses agentes reduziram significativamente sua eficácia e, como consequência, fluoroquinolonas e cefalosporinas de amplo espectro passaram a ser administradas nesses casos. Porém, a seleção gradativa de Salmonella resistente a essas duas classes de antimicrobianos constitui um importante problema de saúde publica, com implicações no tratamento e na prevenção de doenças infecciosas em humanos e animais (EFSA, 2012).

Reveste-se de significância neste estudo o alto índice de resistência à nitrofurantoína (34\%), bem como ao cloranfenicol em $9,8 \%$ das amostras. Ao se avaliar a evolução da resistência a esses dois fármacos no período de análise, foi possível evidenciar uma tendência à diminuição desses percentuais, provavelmente um reflexo da proibição pelo Mapa (Brasil, 2003) da utilização desses fármacos para uso veterinário e de seu emprego na alimentação animal, por meio da Instrução Normativa № 9 de 27/06/2003. Entretanto, é importante considerar a possibilidade de esses dados representarem uma tendência, em que somente resultados de monitoramento contínuo poderão definir o cumprimento dessas normas. Tal assertiva tem por base, em avaliação realizada nos países nórdicos, o conhecimento de que, ao se reduzir a pressão seletiva sobre os microrganismos, mediante a suspensão de uso de alguns antimicrobianos, ocorre o aumento gradativo e finalmente a totalidade de cepas com sensibilidade às drogas analisadas (Newman, 2002).

Ainda na presente avaliação, CRO e CIP apresentaram percentuais de resistência inferiores a $1 \%(0,6$ e $0,2 \%$, respectivamente). Essa resistência se deve a duas cepas de Salmonella ser. Derby com perfil de resistência a quatro marcos (AMP, CEP, CRO, NIT) isoladas de toucinho e à outra (CIP, NAL) isolada de carne suína, ambas no ano de 2006 na região Sul do país, além de uma cepa de Salmonella ser. Schwarzengrund (AMP, CEP e CRO) isolada de linguiça proveniente do Centro-Oeste do Brasil (não evidenciados em tabela). Esses dados devem, portanto, ser considerados um alerta, em face das dificuldades do uso terapêutico empírico, particularmente em relação à CRO e CIP, drogas de escolha no tratamento da salmonelose invasiva no homem (Wong et al., 2013).

Resistência às quinolonas é determinada fundamentalmente por mecanismos mediados por alterações nos sítios de ligação da DNA gyrase e redução destas no interior da bactéria. Inicialmente, o aparecimento de resistência era considerado somente por mutações; atualmente, sabe-se que elementos móveis que carreiam o gene qnr também têm sido descritos como responsáveis por conferir resistência às quinolonas, podendo ser transferidos de forma horizontal (Wang et al., 2004). Considerando esses aspectos, os resultados obtidos, em que algumas cepas multirresistentes incluem em seu perfil, fluoroquinolonas como a ciprofloxacina, representam um quadro preocupante, pois comprovam que à semelhança do que ocorre em diferentes países da Europa, pode haver aumento 
gradativo de Salmonella spp. resistentes a essa classe de drogas (EFSA, 2012).

Além disso, esse aumento da resistência representa elevado risco em curto e médio prazo, particularmente no Brasil. Essa assertiva tem por base o percentual de resistência detectado na presente avaliação para outra quinolona, como o ácido nalidíxico (25\%). O aumento da incidência de cepas resistentes a essa quinolona de primeira geração reveste-se de importância por poder constituir um precursor para resistência a fluoroquinolonas, reduzindo, assim, as opções terapêuticas. Esse aspecto pode ser explicado pelo fato de que cepas previamente resistentes ao ácido nalidíxico podem requerer menor exposição a quinolonas para que sua suscetibilidade seja alterada. Dessa forma, alguns animais podem constituir um reservatório, em que cepas resistentes ao ácido nalidíxico com mutações iniciais no gene gyrA podem persistir e adquirir mecanismos adicionais de resistência após exposição a fluoroquinolonas (Hooper, 2001). Deve-se considerar ainda a possibilidade de a resistência às quinolonas ser também mediada por plasmídios (Souza et al., 2010).

Níveis de resistência para CIP, em torno de $1 \%$, foram observados em países do hemisfério norte no início deste século, conforme relatado por Ângulo et al. (2000), os quais apontaram a emergência de cepas resistentes às fluoroquinolonas entre as salmonelas paratíficas, classe de agentes antimicrobianos empregados como droga de escolha no tratamento de infecções por Salmonella spp. multirresistentes em adultos.

Entre as 257 cepas resistentes, 82 (31,9\%) apresentaram 33 perfis de multirresistência (resistência a três ou mais classes de antimicrobianos), destacando-se por sua prevalência os perfis TCY, NAL, NIT (11 cepas), AMP, CHL, TCY, NIT (9) e AMP, CHL, TCY (8). Entre essas, assinalou-se a ocorrência de quatro cepas pertencentes ao sorovar Typhimurium, isoladas de alimentos industrializados, provenientes da região Sul do Brasil, no ano de 2008, sendo duas com perfis de multirresistência a sete classes (AMP, CHL, TCY, CEP, GEN, NAL, SXT, NIT e AMP,
CHL, TCY, GEN, NAL, SXT, NIT) e outras duas a seis classes (AMP, CHL, TCY, GEN, NAL, NIT e AMP, CHL, TCY, GEN, NAL, SXT).

O crescente isolamento de Salmonella apresentando resistência a um ou vários antimicrobianos provenientes de fontes humana $\mathrm{e}$ animal é considerado alarmante e tem se constituído um importante problema de saúde pública. Muitos fatores têm contribuído para o surgimento de bactérias multirresistentes, todavia a pressão seletiva imposta pela quantidade e diversidade de agentes antimicrobianos (utilizados na agricultura, na medicina humana e na prática veterinária) tem sido apontada como a principal causa do problema. Além da seleção de cepas imposta pelo uso irracional de antimicrobianos, há o agravante da transferência de resistência (Tenover, 2006).

Numerosos estudos, retrospectivos e prospectivos têm demonstrado que o aumento na resistência antimicrobiana ocorre entre bactérias patogênicas e comensais após introdução de um antimicrobiano (Mc Dermott et al., 2003; Tenover, 2006). A observação comum de um relacionamento entre o uso crescente de antimicrobianos de amplo espectro e a emergência da resistência a esses agentes sugere um contínuo ciclo do uso do antibiótico, o desenvolvimento de resistência bacteriana, a eficácia reduzida de antibióticos e a constante necessidade de novas drogas (Mc Dermott et al., 2003).

\section{CONCLUSÕES}

A variedade de sorovares observada neste estudo confirma o papel dos suínos na cadeia alimentar como importantes reservatórios de Salmonella, agravado ainda pelo elevado percentual de cepas resistentes a um ou mais antimicrobianos, alertando para uma condição de risco à saúde pública.

\section{AGRADECIMENTOS}

Aos Laboratórios Centrais de Saúde Pública (Lacen), pela valiosa colaboração, e à Capes, pela concessão da bolsa de mestrado. 


\section{REFERÊNCIAS}

ANGULO, F.J.; JOHNSON, K.R.; TAUXE, R.V.; COHEN, M.L. Origins and consequences of antimicrobial-resistant nontyphoidal Salmonella: implications for the use of fluoroquinolones in food animals. Microb. Drug. Resist., v.6, p.77-83. 2000.

BESSA, M.C.; COSTA, M.; CARDOSO, M. Prevalência de Salmonella sp em suínos abatidos em frigoríficos do Rio Grande do Sul. Pesqui. Vet. Bras., v.24, p.80-84, 2004.

BOTTELDOORN, N.; HERMAN, L.; RIJPENS, N.; HEYNDRICKX, M. Phenotypic and Molecular Typing of Salmonella strains reveals different contamination sources in two commercial pig slaughterhouses. Appl. Environ. Microbiol., v.70, p.5305-5314, 2004.

BRASIL. Ministério da Agicultura Pecuária e Abastecimento. Instrução normativa $n .{ }^{\circ} 9$ de 27 de junho de 2003. Proíbe a fabricação, a manipulação, $\mathrm{o}$ fracionamento, a comercialização, a importação e o uso dos princípios ativos cloranfenicol e nitrofuranos e os produtos que contenham estes princípios ativos, para uso veterinário e suscetível de emprego na alimentação de todos os animais e insetos. Diário Oficial da União, Brasília, DF, 30 jun. 2003. Seção 1, p. 5.

CASTAGNA, S.M.F.; SCHWARZ, P.; CANAL, C.W.; CARDOSO, M.R.I. Prevalência de suínos portadores de Salmonella sp. ao abate e contaminação de embutidos tipo frescal. Acta Sci. Vet., v.32, p.141-147, 2004.

COMMUNITY summary report on trends and sources of zoonoses and zoonotic agents and food-borne outbreaks in the European Union in 2008. EFSA J., v.8, p.1496. 2010. Disponível em:

$<$ http://www.efsa.europa.eu/en/efsajournal/pub/1 496.htm>. Acessado em: 24 jun. 2012.

COSTA, G.A.; HOFER, E. Isolamento $e$ identificação de enterobactérias. 1972. 120f. (Monografia) - Instituto Oswaldo Cruz, Rio de Janeiro, RJ.
EUROPEAN Union summary report on antimicrobial resistance in zoonotic and indicator bacteria from humans, animals and food in 2010. EFSA J., v.10, p.2598. 2012. Disponível em: $<$ www.efsa.europa.eu/efsajournal $>$. Acessado: 24 jan. 2013.

GRIMONT, P.A.D.; WEILL, F. Antigenic formulae of the Salmonella serovars. 9.ed. Paris: Institut Pasteur, 2007. 166p. Disponível em: $<$ http://www.pasteur.fr/sante/clre/cadrecnr/salmo ms/WKLM_2007.pdf.>. Acessado em: 22 nov. 2010.

HOOPER, D.C. Emerging mechanism of fluoroquinolone resistance. Emerg. Infect. Dis., v.7, p.337- 41. 2001.

MARQUES, S.C.; BOARI, C.A.; BRCKO, C.C. et al. Avaliação higiênico-sanitária de linguiças tipo frescal comercializadas nos municípios de Três Corações e Lavras MG. Ciênc. Agrotec.,v.30, p.1120-1123. 2006.

MC DERMOTT, P.F.; WALKER, R.D.; WHITE, D.G. Antimicrobials: modes of action and mechanisms of resistance. Int. J. Toxicol., v.22, p.135-143. 2003.

MERCADO interno de carne suína: produção brasileira de carne suína 2004-2011. ABIPECS, 2011. Disponível em: $<$ http://www.abipecs.org.br/pt/estatisticas/merca do-interno.html>. Acessado em: 06 fev. 2013.

NEWMAN, M. Antibiotic resistance is a reality: novel techniques for overcoming antibiotic resistance when using new growth promoters. Nutritional biotechnology in the feed and food industries. In: THE ALLTECH ANNUAL INTERNATIONAL SYMPOSIUM, 18., 2002. Proceedings..., [s.1.]: Alltech, 2002. p.97-106.

PERFORMANCE standards for antimicrobial susceptibility testing. Wayne: Clinical and Laboratory Standards Institute, 2012. M100-S21. v.31.

PRELIMINARY foodnet data on the incidence of infection with pathogens transmitted commonly through food - 10 States, 2008. Atlanta, U.S.A.: Centers for Disease Control and Prevention, 2009. Disponível em: $<\mathrm{http} / / / \mathrm{www} . c d c . g o v / \mathrm{mmwr} / \mathrm{preview} / \mathrm{mmwrhtml}$ $/ \mathrm{mm} 5813 \mathrm{a} 2 . \mathrm{htm}$ ?s_cid=mm5813a2_e $>$.

Acessado em: 28 jan. 2011. 
RODRIGUES, D.P.; REIS, E.M.F.; COSTA, R.G. et al. Relatório anual de atividades do Laboratório de Referência Nacional de Enteroinfeç̧ões Bacterianas - 2013. [s.1.]: CGLAB/DEVEP/SVS, [2014]. (in press).

RODRIGUES, D.P. Perspectivas atuais e falhas no diagnóstico antigênico de Salmonella spp.: importância no reconhecimento dos sorovares circulantes, emergentes e exóticos. In: Memoria Del Seminário Internacional Sobre Salmonelose Aviar, 2011, Rio de Janeiro. Anais... Rio de Janeiro, 2011. p.1-7. 1 CD-ROM.

ROSSI, A.A. Biossegurança em frangos de corte e saúde pública: limitações, alternativas e subsídios na prevenção de salmoneloses. 2005. 11f. Dissertação (Mestrado em Agroecossistemas) - Universidade Federal de Santa Catarina, PR.

SEIXAS, F.N.; TOCHETTO, R.; FERRAZ, S.M. Presença de Salmonella $s p$. em carcaças suínas amostradas em diferentes pontos da linha de processamento. Ciênc. Anim. Bras., v.10, p.634640, 2009.

SILVA, M.C. Prevalência de Salmonella sp. em suínos abatidos no estado de Mato Grosso. 2008. 68f. Dissertação (Mestrado em Ciência Animal) - Universidade Federal do Mato Grosso, Cuiabá, MS.

SOUZA, R.B.; MAGNANI, M.; OLIVEIRA, T.C.R.M. Mecanismos de resistência às quinolonas em Salmonella spp. Semina: Ciênc. Agr., v.31, p.413-428, 2010.
SPRICIGO, D.A.; MATSUMOTO, S.R.; ESPÍNDOLA, M.L.; FERRAZ, S.M. Prevalência, quantificação e resistência a antimicrobianos de sorovares de Salmonella isolados de linguiça frescal suína. Ciênc. Tecnol. Aliment., v.28, p.779-785, 2008.

STEVENS, M.P.; HUMPHREY, T.J.; MASKELL, D.J. Molecular insights into farm animal and zoonotic Salmonella infections. Philos. Trans. R. Soc. Lond. B., v.364, p.27092723. 2009.

TENOVER, F.C. Mechanisms of antimicrobial resistance in bacteria. Am. J. Med., v.119, p.3-10, 2006.

TESSMANN, C.; ZOCCHE, F.; LIMA, A.S. et al. Ocorrência e perfil de sensibilidade a antibióticos de Salmonella spp. isolada em cortes de carne suína comercializadas em feiras-livres de Pelotas (RS). Bol. CEPPA, v.26, p.307-313, 2008.

WANG, M.; SAHM, D.F.; JACOBY, G. A.; HOOPER, D.C. Emerging plasmid-mediated quinolone resistance associated with the qnr gene in Klebsiella pneumoniae clinical isolates in the United States. Antimicrob. Agents Chemother., v.48, p.1295-1299. 2004.

WEILL, F.X.; GUESNIER, F.; GUIBERT, V. et al. Multidrug resistance in Salmonella enterica serotype typhimurium from humans in France (1993 to 2003). J. Clin. Microbiol., v.44, p.700708, 2006.

WONG, M.H.; ZENG, L.; LIU, J.H.; CHEN, S. Characterization of salmonella food isolates with concurrent resistance to ceftriaxone and ciprofloxacin. Foodborne Pathog Dis. v.10, p.42-46. 2013 